\title{
ДИНАМИКА МЕТАПРЕДМЕТНЫХ РЕЗУЛЬТАТОВ НАЧАЛЬНОГО ОБРАЗОВАНИЯ НА ЭТАПЕ ПЕРЕХОДА В ОСНОВНУЮ ШКОЛУ
}

\author{
В.В. РУБЦОВ , Е.В. ВЫСОЦКАЯ ${ }^{\mathrm{a}}$ А.З. ЗАК \\ М.А. ЯНИШЕВСКАЯ ${ }^{\text {a }}$ И.М. УЛАНОВСКАЯ ${ }^{a}$
}

"ФГБНУ «Психологический институт Российской академии образования», 125009, Россия, Москва, ул. Моховая, Ә. 9, стр. 4

\begin{abstract}
Резюме
В статье представлены данные диагностического исследования по определению уровня сформированности таких метапредметных образовательных результатов, как освоение начальных форм познавательной рефлексии, освоение способов решения проблем поискового характера и умение планировать у учащихся 5-х и 6-х классов. В исследовании приняли участие 517 учащихся 14 школ Москвы и Зеленограда. Метапредметные образовательные результаты определялись с помощью методики «Перестановки» (автор - А.З. Зак). В качестве «точки отсчета» взяты данные предварительной диагностики, полученной при обследовании с помощью методики «Перестановки» более 2000 выпускников начальной школы в 2011 г.. Рассмотрена динамика метапредметных результатов за время обучения в 5-м и 6-м классах. Выделены качественные уровни сформированности познавательной рефлексии (содержательная рефлексия, формальная рефлексия, рефлексия не сформирована), умения решать проблемы поискового характера (решение осуществляется общим способом, решение осуществляется частным способом, не сформирован способ решения поисковых задач) и умения планировать (целостное планирование, эмпирическое планирование, планирование не сформировано). Показано, что уровень сформированности метапредметных результатов пятиклассников достаточно низок: содержательная рефлексия отмечается у 7.4\% детей, умение решать проблемы общим способом - у $30.5 \%$ детей, целостное планирование - у 10.2\% детей. Отмечается положительная динамика за время обучения в 6-м классе, однако уровень познавательной рефлексии, умения решать проблемы поискового характера и умения планировать продолжает оставаться недостаточно высоким. Содержательную рефлексию демонстрируют $11.7 \%$ шестиклассников, умение решать проблемы общим способом - 46.1\% детей, целостное планирование - $28.1 \%$. В заключение проводится сравнение полученных нами данных с результатами выполнения методики «перестановки» выпускниками начальной школы в 1980 г. Обсуждаются направления дальнейших исследований.
\end{abstract}

Ключевые слова: метапредметные образовательные результаты, познавательная рефлексия, умение планировать, умение решать проблемы поискового характера, этап перехода в основную школу.

Исследование выполнено при финансовой поддержке РФФИ, проект № h16-06-00926-ОГН. 
В новом образовательном Стандарте начального образования (Федеральный..., 2009) сформулированы требования, никогда ранее не присутствовавшие в наших образовательных документах. В этих требованиях впервые зафиксировано одно из важнейших положений культурно-исторического подхода Л.С. Выготского к проблеме соотношения обучения и развития (Выготский, 1996). Согласно Стандарту важнейшим результатом обучения в начальной школе должны стать сформированные метапредметные компетенции. Метапредметные результаты являются индикатором когнитивного, социального и деятельностного развития младшего школьника в процессе обучения. Таким образом, новые требования переносят акцент с педагогических результатов, каковыми являются знания, умения, навыки, на результаты психологические, интерпретируемые в категориях развития.

Очевидно, что постановка новых образовательных задач требует разработки новых методов оценки результата. Классические тесты интеллекта непригодны для диагностики развивающего эффекта образования (независимость от среды - главная характеристика тестов интеллекта, а для оценки развивающего эффекта образования среда школы является главным фактором влияния). Не годятся также и традиционные педагогические критерии, такие как успеваемость по школьным предметам, так как формирование метапредметных результатов - особая образовательная задача, не сводимая к освоению конкретных предметных знаний и способов действия. Поэтому в 20102012 гг. коллективом сотрудников Психологического института РАО был разработан пакет методов для оценки сформированности всех 16 метапредметных результатов, сформулированных в тексте Стандарта, у выпускников начальной школы. Общим принципом, положенным в основу разработки методик оценки метапредметных результатов, было то, что они моделировали некоторую учебную ситуацию, т.е. требовали от учащихся продемонстрировать сформированный у них способ действия. Каждый метапредметный результат оценивается не только количественно, но и качественно, на разном материале и на заданиях разной трудности. Поэтому по каждому результату мы получили целый комплекс показателей. Методики были апробированы на 43 школах г. Москвы (около 2000 детей). Результаты этой апробации были подвергнуты всестороннему статистическому анализу. Была доказана валидность и надежность предложенных методов и процедур. Это значит, что разработанные методы являются надежным инструментом для дифференцированной количественной и качественной оценки сформированности всего набора метапредметных компетенций.

На этом - предварительном - этапе диагностики было показано, что большинство метапредметных компетенций у выпускников начальной школы сформировано на довольно низком уровне (Улановская, 2014). При этом были обнаружены значительные, статистически значимые различия по изучаемым показателям в школах с различными образовательными программами. Т.е. выпускники школ, работающих по «традиционным» учебным программам, не владеют всеми метапредметными компетенциями на том уровне, который мог бы обеспечить их относительно легкое вхождение в основную школу с ее требованиями и 
новым предметным содержанием (Зак, Сорокова, 2017; Высоцкая и др., 2017). Поэтому на учителей основной школы ложится дополнительная задача помимо организации учебного процесса в рамках своего предмета компенсировать и стимулировать формирование тех метапредметных компетенций, которые не были полностью освоены учащимися на этапе начальной школы.

Целью настоящего исследования явилось изучение динамики основных когнитивных метапредметных результатов начального образования на этапе перехода в основную школу (5-6-е классы).

\section{Задачи исследования:}

1. Оценить уровень сформированности когнитивных метапредметных результатов начального образования (предварительный этап диагностики).

2. Оценить динамику метапредметных результатов на переходе в основную школу - в 5-6-х классах (первый и второй этапы диагностики).

\section{Диагностическая процедура}

Для оценки эффективности решения педагогами основной школы задачи «доразвития» метапредметных компетенций учащихся - выпускников начальной школы нами была спроектирована следующая диагностическая процедура.

На первом этапе (2013/14 учебный год) нами была проведена диагностика исходного уровня сформированности метапредметных результатов НОО у учащихся 5-х классов. В обследовании приняли участие учащиеся 14 школ гг. Москвы и Зеленограда, всего 699 человек. Данные диагностики были представлены учителям и администрации школ. После обсуждения полученных результатов школы приняли программы целенаправленного формирования базовых метапредметных компетентностей у учащихся в ходе обучения в 6-м классе. Эти программы разрабатывались школами самостоятельно, в зависимости от того, формированию каких метапредметных результатов предполагалось уделять особое внимание. Решение о «предпочтительных» метапредметных результатах принималось учителями и администрацией школы. Программы внедрялись в течение полного учебного года.

Второй этап диагностики осуществлялся в мае 2015 г., т.е. через год после первой диагностики и введения систем коррекционных мероприятий, осуществлявшихся на протяжении всего учебного года. Использовался тот же диагностический инструментарий, что и на первом этапе исследования. При обработке данных учитывались результаты только тех учащихся, которые участвовали в обоих этапах диагностики. Таким образом, сравнение результатов двух этапов диагностики позволяет оценить динамику развития метапредметных компетенций у учащихся 6-х классов и, косвенно, эффективность коррекционных программ основной школы.

Для статистического анализа результатов второго этапа диагностики метапредметных компетенций были использованы данные 675 учеников 6-х классов из 14 образовательных учреждений. Для оценки динамики развития 
метапредметных компетенций мы учитывали результаты тех 517 учеников, которые полностью прошли оба этапа диагностики (и в 2014, и в 2015 г.).

В рамках данной статьи будут представлены результаты диагностики следующих метапредметных компетенций:

- освоение способов решения проблем поискового характера;

- формирование умения планировать, контролировать и оценивать учебные действия в соответствии с поставленной задачей и условиями ее реализации;

• освоение начальных форм познавательной рефлексии.

\section{Методика}

Для оценки этих метапредметных компетенций рассмотрим результаты, полученные по методике «Перестановки» (автор - А.З. Зак). Эта методика позволяет различить способ, который использует ребенок для решения проблем поискового характера (Давыдов, 2004; Зак, Сорокова, 2017). При эмпирическом способе существенные и несущественные отношения в условиях задачи не различаются, ее решение реализуется путем проб и ошибок, способ либо вообще не осознается, либо в нем осознается лишь конкретный состав операций и он целиком не планируется. При теоретическом способе выявляются существенные отношения в условиях задачи, решение планируется целиком и осуществляется без проб и ошибок, в успешном способе решения осознаются не только конкретные операции, но, главное, его связь с существенными отношениями. В этом случае решение задачи включает теоретическую часть (когда содержание задачи исследуется с помощью особых познавательных действий) и практическую (когда реально достигается конкретный результат). Обобщенный подход к решению задач включает содержательный анализ, познавательную рефлексию и содержательное планирование (Зак, 1984; Зак, Улановская, 2017).

Освоенность начальных форм познавательной рефлексии характеризуется возможностью ребенка содержательно обобщать способ действий при решении задач, т.е. раскрывать существенную общность способов своих действий при решении задач одного рода и выделять принципиальное различие реализованных способов при решении задач разного рода. В этом случае учащийся опирается на знание оснований своих действий и того, почему при решении задач он действовал тем или иным способом.

Освоенность способов решения проблем поискового характера характеризуется возможностью осуществлять при решении задач содержательный (теоретический) анализ их условий, связанный с выделением существенных отношений данных. В результате успешно решаются все задачи предложенного класса. Факт неуспешного решения одной или нескольких задач предложенного класса свидетельствует об отсутствии содержательного анализа.

Сформированность способности действовать «в уме» характеризуется возможностью планировать при решении задач (путем оперирования «в уме») сразу все требуемые действия до их реального выполнения. 
Методика строится на материале наглядно-образных задач и включает три задания (Зак, Улановская, 2017).

Задание 1 предназначено для определения уровня освоения начальных форм познавательной рефлексии при решении задач в наглядно-образной форме. Детям нужно решить три задачи (две построены по одному принципу, одна - по другому), а затем выбрать одно мнение о них из пяти предложенных. В этих мнениях от лица детей даны формулировки схожести или различий между способами решения предложенных задач.

Если, верно решив три задачи, ребенок выбирает правильное мнение, то в этом случае принимается, что при решении имела место содержательная рефлексия (третий уровень рефлексии).

Если, верно решив три задачи, ребенок выбирает неправильное мнение, то в этом случае принимается, что при решении имела место формальная рефлексия (второй уровень рефлексии).

Если какая-то из задач решена неверно, то выбор правильного мнения не свидетельствует о проявлении ни формальной, ни, тем более, содержательной рефлексии (первый уровень рефлексии).

Таким образом, для определения уровня сформированности познавательной рефлексии необходимо учитывать оба критерия: учащийся, владеющий содержательной рефлексией (третий уровень), должен не только солидаризироваться со сформулированным способом действия, но и продемонстрировать его осознание в собственном решении.

Задание 2 предназначено для определения уровня «освоения способов решения проблем поискового характера» при решении задач в наглядно-образной форме. После усвоения - при выполнении задания 1 - правила перестановки фигур (обмен местами) детям нужно решить три задачи, построенные по единому принципу.

Если ребенок решил верно все три задачи, то в этом случае принимается, что решение основано на выделении существенных отношений, лежащих в основе единого принципа решения, - это означает, что решение осуществлялось общим способом (третий уровень анализа).

Если ребенок не решил верно три задачи, а решил верно любые две или одну из трех задач, то в этом случае принимается, что решение не основано на выделении существенных отношений, лежащих в основе единого принципа решения, - это означает, что решение осуществлялось частным способом (второй уровень анализа).

Если учащийся не справился с решением ни одной задачи, то у него не сформирован способ решения поисковых задач (первый уровень анализа).

Задание 3 предназначено для определения уровня развития способности действовать «в уме» как исходной для формирования у детей регулятивных универсальных учебных действий, связанных с планированием, контролем и оценкой предметных учебных действий. После усвоения правила перестановки фигур (обмен местами) детям нужно решить задачи, где, в отличие от предыдущих заданий, в условиях задач представлено больше фигур и где требуется выполнить больше комбинаторных действий. Отмеченные обстоятельства 
существенно затрудняют оперирование элементами условий задач (геометрические фигуры и цифры) в мысленном плане.

Успешное решение четырех или трех задач этого задания характеризует сформированность высокого уровня развития способности действовать «в уме» (третий уровень - целостное планирование), успешное решение двух задач - эмпирическое планирование (второй уровень), успешное же решение только одной задачи или вообще отсутствие успешного решения какой-либо задачи этого задания свидетельствует о сформированности лишь частичного уровня развития этой способности (первый уровень).

Обработка данных проводилась с помощью программы SPSS. Достоверность различий между результатами предварительной диагностики и первого этапа диагностики определялась с помощью критерия Манна-Уитни, для сравнения данных первого и второго этапов использовался критерий знаковых рангов Вилкоксона.

\section{Анализ результатов}

\section{Этап предварительной диагностики}

Для оценки эффективности работы основной школы в плане коррекции уровня сформированности метапредметных результатов сначала проанализируем данные предварительной диагностики, полученные нами на большой выборке выпускников начальной школы. Эти данные собраны в 2011 г., когда новые стандарты только внедрялись в образовательный процесс начальной школы. Таким образом, эти данные характеризуют метапредметный результат традиционного начального образования, перед которым еще не ставилась специальная задача формирования метапредметных компетенций.

Показатели сформированности метапредметных результатов у выпускников начальной школы приведены в таблице 1.

Из данных таблицы следует, что относительно более высокие значения характеризуют сформированность компетенции «освоение способов решения проблем поискового характера». Среднее число решенных задач по этому

Таблица 1

Описательная статистика по показателям сформированности отдельных метапредметных результатов на этапе предварительной диагностики

\begin{tabular}{|l|c|c|c|c|c|c|}
\hline \multicolumn{1}{|c|}{ Метапредметные результаты } & Min & Max & M & SD & Асимметрия & Эксцесс \\
\hline $\begin{array}{l}\text { Освоение начальных форм } \\
\text { познавательной рефлексии }\end{array}$ & 0 & 2 & 0.59 & 0.642 & 0.614 & -0.604 \\
\hline $\begin{array}{l}\text { Освоение способов решения } \\
\text { проблем поискового характера }\end{array}$ & 0 & 3 & 1.62 & 1.256 & -0.166 & -1.615 \\
\hline Умение планировать & 0 & 4 & 0.68 & 1.001 & 1.479 & 1.478 \\
\hline Стандартная ошибка & & & & & 0.071 & 0.142 \\
\hline
\end{tabular}


показателю чуть больше половины (1.62 при максимуме 3). Самые низкие результаты характеризуют сформированность «умения планировать». В среднем учащиеся решили лишь 17\% задач на планирование (0.68 из 4 максимально возможных).

Распределение учащихся - выпускников начальной школы по уровням сформированности этих метапредметных результатов представлено в таблице 2.

Таким образом, результаты предварительной диагностики (данные таблиц 1 и 2) показывают, что на выходе из начальной школы метапредметные компетенции, связанные с теоретическим планированием и рефлексией, сформированы недостаточно. Несколько лучше других оказался сформирован показатель «освоение способов решения проблем поискового характера»: доля детей, которые способны использовать общий способ решения задачи, составила $36.7 \%$.

Отрицательные значения эксцесса для компетенций «освоение начальных форм познавательной рефлексии» и «освоение способов решения проблем поискового характера» означают, что эти величины имеют «двугорбое» распределение, т.е. дети «распадаются» на две неравные группы: в одной (многочисленной) группе уровень сформированности низкий, в другой (малочисленной) - относительно высокий, с «провалом» в середине. Этот факт подтверждается распределением числа школьников по уровням сформированности метапредметных результатов. Можно отметить, что у значительного большинства детей (от 45 до 82\%) данные результаты или не сформированы вовсе, или сформированы слабо. Владеют познавательной рефлексией и теоретическим планированием менее 10\% выпускников начальной школы. Результаты сформированности компетенции «освоение способов решения проблем поискового характера» прямо указывают на наличие на выходе из начальной школы двух групп - с высоким и низким уровнем сформированности этого показателя.

Приведенные данные говорят о том, что выпускники начальной школы недостаточно подготовлены к усвоению материала основной школы, ведь именно сформированность метапредметных результатов начального образования обеспечивает успешность дальнейшего учебного продвижения в основной школе.

Таблица 2

Распределение детей по уровням сформированности метапредметных образовательных результатов на этапе предварительной диагностики, \%

\begin{tabular}{|l|c|c|c|}
\hline \multicolumn{1}{|c|}{ Метапредметные результаты } & 3-й уровень & 2-й уровень & 1-й уровень \\
\hline $\begin{array}{l}\text { Освоение начальных форм } \\
\text { познавательной рефлексии }\end{array}$ & 7.8 & 39 & 53.2 \\
\hline $\begin{array}{l}\text { Освоение способов решения } \\
\text { проблем поискового характера }\end{array}$ & 36.7 & 18.4 & 44.9 \\
\hline Умение планировать & 7.5 & 10.7 & 81.8 \\
\hline
\end{tabular}


Как мы уже отмечали, полученные данные характеризуют те метапредметные результаты, которые складывались стихийно. Однако на их основе можно сделать два вывода:

1) традиционная начальная школа не обеспечивала полноценного формирования когнитивных метапредметных компетенций;

2) для формирования метапредметных результатов требуются особые образовательные условия. Причем набор этих условий может различаться в зависимости от того, на формирование каких компетенций нацелено внимание школы. Это предположение основано на том факте, что по разным метапредметным результатам мы получаем большой разброс показателей сфомированности в рамках одной образовательной среды школы.

\section{Первый этап диагностики}

В 2014 г. мы провели диагностику сформированности метапредметных результатов начального образования у выпускников 5-х классов. В этих классах впервые в образовательном процессе на начальной ступени образования ставилась задача формирования метапредметных результатов.

Результаты сформированности отдельных метапредметных результатов у пятиклассников приведены в таблице 3 .

В таблице 4 показано распределение учащихся, продемонстрировавших достижение разных уровней сформированности когнитивных метапредметных результатов.

Сопоставление данных таблиц 3 и 4 (первый этап диагностики) с данными таблиц 1 и 2 (этап предварительной диагностики) позволяет констатировать, что результаты выпускников 5-х классов не демонстрируют статистически значимого прироста по сравнению с результатами четвероклассников, принятых нами за «точку отсчета». Сформированность компетенции «освоение начальных форм познавательной рефлексии» осталась практически на том же уровне (0.63 по сравнению с 0.59 в предварительном диагностическом исследовании), а значение показателя «освоение способов решения проблем поискового характера» даже уменьшилось (с 1.62 до 1.51). Увеличилось лишь

Таблица 3

Описательная статистика по показателям сформированности отдельных метапредметных результатов на первом этапе диагностики

\begin{tabular}{|l|c|c|c|c|c|c|}
\hline \multicolumn{1}{|c|}{ Метапредметные результаты } & Min & Max & M & SD & Асимметрия & Эксцесс \\
\hline $\begin{array}{l}\text { Освоение начальных форм } \\
\text { познавательной рефлексии }\end{array}$ & 0 & 2 & 0.63 & 0.659 & 0.574 & -0.677 \\
\hline $\begin{array}{l}\text { Освоение способов решения } \\
\text { проблем поискового характера }\end{array}$ & 0 & 3 & 1.51 & 1.233 & -0.035 & -1.601 \\
\hline Умение планировать & 0 & 4 & 0.95 & 1.143 & 0.964 & -1.169 \\
\hline Стандартная ошибка & & & & & 0.111 & 0.222 \\
\hline
\end{tabular}


Таблица 4

Распределение детей по уровням сформированности метапредметных образовательных результатов на первом этапе диагностики, \%

\begin{tabular}{|l|c|c|c|}
\hline \multicolumn{1}{|c|}{ Метапредметные результаты } & 3-й уровень & 2-й уровень & 1-й уровень \\
\hline $\begin{array}{l}\text { Освоение начальных форм } \\
\text { познавательной рефлексии }\end{array}$ & 7.4 & 41.4 & 51.2 \\
\hline $\begin{array}{l}\text { Освоение способов решения } \\
\text { проблем поискового характера }\end{array}$ & 30.5 & 18.8 & 50.8 \\
\hline Умение планировать & 10.2 & 12.1 & 77.7 \\
\hline
\end{tabular}

значение показателя «умение планировать» (с 0.68 до 0.95). Однако все эти изменения статистически незначимы (различия между выборками определялись по критерию Манна-Уитни). Практически не изменился и характер распределения учащихся по уровням сформированности этих результатов. У большинства учащихся (50-78\%) метапредметные образовательные результаты не сформированы или сформированы на первом (низком) уровне.

Отсутствие позитивной динамики в «освоении начальных форм познавательной рефлексии» вызывает особое удивление в связи с тем, что формально этому мыслительному действию в основной школе придается особое значение. Так, рефлексия является обязательным этапом «урока по ФГОС», что позволяет нам ожидать более выраженной положительной динамики этой способности к концу 5-го класса. Возможно, проблема лежит в различиях в понимании самого смысла понятия «рефлексия» в психологической науке и педагогической практике. Так, по В.В. Давыдову познавательная рефлексия, на формирование которой должно быть направлено обучение, представляет собой способность осознания человеком оснований своих собственных мыслительных действий (Давыдов, 2004, с. 123). Это же понимание отражено и в методических документах. Так, в «Примерной основной образовательной программе образовательного учреждения» (важном методическом документе) указано, что «одним из центральных психологических новообразований, формируемых на начальном уровне образования, является "рефлексия содержания, оснований и способов действий” (Савинов, 2010). Однако на уроке формирование рефлексии, как правило, сводится к постановке учителем вопросов типа «Какая задача была поставлена перед нами на уроке? Решили ли мы ее?», «Оправдались ли ваши ожидания от урока?», «Что бы вы хотели исследовать еще?», «Как вы можете оценить свою работу?» (Белова и др., 2016). Эти примеры вопросов не придуманы нами. Они взяты из методических разработок Московского городского методического центра. Такие вопросы отрывают рефлексию от учебного действия. Она перестает быть средством мыслительной деятельности.

Единственный метапредметный результат, по которому отмечена некоторая позитивная динамика, это «формирование умения планировать». Для этого показателя изменения значимы на уровне тенденции (критерий Манна-Уитни $U=0.43, p=0.05)$. 
Таким образом, сравнение результатов учащихся, прошедших обучение в начальной школе в период, когда задача формирования метапредметных результатов вообще не ставилась (этап предварительной диагностики 2011 г.), и результатов пятиклассников, обучавшихся в начальной школе по новым ФГОСам (первый этап диагностики), не показало статистически значимых различий. Обучение в 5-м классе (переход на новую ступень образования) также не повлияло на качество формирования метапредметных результатов. Можно предположить, что в массовой школе отсутствуют средства, адекватные для эффективного формирования когнитивных метапредметных результатов.

\section{Второй этап диагностики}

Результаты сформированности отдельных метапредметных результатов у шестиклассников приведены в таблице 5.

В таблице 6 показано распределение учащихся, продемонстрировавших достижение разных уровней сформированности когнитивных метапредметных результатов в 6-м классе.

Результаты показывают определенную положительную динамику всех метапредметных результатов, различия статистически значимы. Достоверность

Таблица 5

Описательная статистика по показателям сформированности отдельных метапредметных результатов на втором этапе диагностики

\begin{tabular}{|l|c|c|c|c|c|c|}
\hline \multicolumn{1}{|c|}{ Метапредметные результаты } & Min & Max & M & SD & Асимметрия & Эксцесс \\
\hline $\begin{array}{l}\text { Освоение начальных форм } \\
\text { познавательной рефлексии }\end{array}$ & 0 & 2 & 0.77 & 0.623 & 0.210 & -0.589 \\
\hline $\begin{array}{l}\text { Освоение способов решения } \\
\text { проблем поискового характера }\end{array}$ & 0 & 3 & 2.10 & 0.881 & -0.197 & -1.681 \\
\hline Умение планировать & 0 & 4 & 1.40 & 1.258 & 0.343 & -1.161 \\
\hline Стандартная ошибка & & & & & 0.111 & 0.222 \\
\hline
\end{tabular}

Таблица 6

Распределение детей по уровням сформированности метапредметных образовательных результатов на втором этапе диагностики, \%

\begin{tabular}{|l|c|c|c|}
\hline \multicolumn{1}{|c|}{ Метапредметные результаты } & 3-й уровень & 2-й уровень & 1-й уровень \\
\hline $\begin{array}{l}\text { Освоение начальных форм } \\
\text { познавательной рефлексии }\end{array}$ & 11.7 & 55.5 & 32.8 \\
\hline $\begin{array}{l}\text { Освоение способов решения } \\
\text { проблем поискового характера }\end{array}$ & 46.1 & 20.5 & 33.2 \\
\hline Умение планировать & 28.1 & 19.5 & 52.3 \\
\hline
\end{tabular}


различий определялась с использованием критерия знаковых рангов Вилкоксона. Данные приведены в таблице 7.

Сравнение данных первого и второго этапов диагностики показывает следующее.

1. Сравнивая данные таблиц 3 и 5, можно заметить, что показатель «умение планировать» вырос почти в полтора раза - с 0.95 до 1.40. Метапредметный результат «освоение начальных форм познавательной рефлексии» показал наименьшую позитивную динамику, он увеличился с 0.63 до 0.77.

2. По данным таблиц 4 и 6 число детей, у которых сформирована содержательная рефлексия способа решения задач (3-й уровень), статистически значимо не изменилось. Сформированность 3-го уровня означает, как мы уже отмечали, что эти дети умеют содержательно обобщать способ действий при решении задач, т.е. раскрывать существенную общность способов своих действий при решении задач одного рода и выделять принципиальное различие реализованных способов при решении задач разного рода. Таким образом, можно констатировать, что обучение в 6-м классе в школах, где специально была организована работа по формированию метапредметных компетенций, не дало результата в плане развития содержательной рефлексии.

3. По данным таблиц 4 и 6 количество школьников, которые формально выделяют способ решения, т.е. находятся на 2-м уровне развития рефлексии, увеличилось в 1.3 раза. Эти дети ориентируются на внешние, несущественные признаки задачи и строят свои действия, ориентируясь на них.

4. По данным таблицы 6 более половины учащихся, заканчивающих 6-й класс, владеют основами познавательной рефлексии на формальном (2-м) уровне. Около трети детей (32.8\%) находятся на 1-м уровне сформированности познавательной рефлексии, т.е. вообще не способны выделить способ решения задачи.

5. Сравнение двух этапов диагностики показывает, что если в 5-х классах преимущественно был представлен 1-й уровень сформированности рефлексии, то в 6-х классах большинство учащихся продемонстрировали 2-й уровень сформированности рефлексии. Таким образом, обучение в 6-м классе (включающее коррекционные мероприятия, направленные на формирование

Таблица 7

Результаты сравнения данных первого и второго этапов диагностики по критерию знаковых рангов Вилкоксона

\begin{tabular}{|l|c|c|c|}
\hline & $\begin{array}{c}\text { Освоение начальных } \\
\text { форм познавательной } \\
\text { рефлексии }\end{array}$ & $\begin{array}{c}\text { Освоение способов } \\
\text { решения проблем } \\
\text { поискового характера }\end{array}$ & $\begin{array}{c}\text { Умение } \\
\text { планировать }\end{array}$ \\
\hline $\mathrm{Z}$ & -3.803 & -7.834 & -5.659 \\
\hline $\begin{array}{l}\text { Асимптотическая } \\
\text { значимость } \\
(2 \text {-сторонняя })\end{array}$ & 0.000 & 0.000 & 0.000 \\
\hline
\end{tabular}


метапредметных результатов) привело к формированию формального способа действия, которое основывается на выделении внешних, несущественных признаков, в ущерб содержательной рефлексии.

6. Умение планировать, понимаемое как разработка целостной программы выполнения практических действий, исходя из представлений об искомом результате, несмотря на наиболее интенсивный рост, остается весьма слабо сформированным. Больше половины (52\%) шестиклассников находятся на первом (самом низком) уровне освоения планирования, когда каждый шаг решения задачи намечается и выполняется отдельно без опоры на представление о результате.

7. По данным таблиц 4 и 6 число школьников, продемонстрировавших теоретический подход к решению задачи (3-й уровень), выросло за время обучения в 6 -м классе в 2.75 раза и достигло $28 \%$.

8. По данным таблицы 5 эксцесс для показателя «умение планировать» имеет значение -1.16 . Это значит, что распределение является двугорбым, в котором выражены минимальные и максимальные значения относительно средних.

9. «Освоение способов решения проблем поискового характера» показывает, способен ли ученик выделить в наборе задач общий принцип их решения, или он решает каждую задачу по отдельности. Сравнение данных, приведенных в таблицах 1, 3 и 5, показывает, что характер распределения оставался практически неизменным на всех этапах диагностики: с пренебрежимо малой асимметрией и значительным отрицательным эксцессом. Это означает, что средние значения показателя наблюдаются у школьников сравнительно редко, а максимальные и минимальные достигаются гораздо чаще и с почти одинаковой частотой. На этапе предварительной диагностики и на первом этапе исследования наблюдалось смещение в сторону минимальных значений (асимметрия принимала отрицательные значения -0.166 и -0.035 соответственно), на втором этапе диагностики - в сторону максимальных (значение коэффициента асимметрии изменило знак и стало 0.343). Это означает, что в целом наблюдается положительная динамика в освоении способов решения проблем поискового характера на этапе перехода в основную школу.

10. Сравнивая данные таблиц 2,4 и 6 , можно констатировать, что обучение в 5-м классе не способствовало освоению теоретического способа решения поисковых задач: в сравнении с нормой (в качестве нормы рассматриваем данные предварительной диагностики выпускников начальной школы) число пятиклассников, владеющих теоретическим способом решения поисковых задач, снизилось с 36.7 до 30.5\%. Однако в 6-м классе отмечается значительный рост (в 1.5 раза) числа детей, достигших 3 -го уровня освоения этого метапредметного результата.

11. Сравнивая данные таблиц 2, 4 и 6, можно заметить, что в 5-м классе число детей, не способных осуществлять при решении задач содержательный, теоретический анализ их условий (1-й уровень), возрастает и достигает 51\% от всей выборки. В конце шестого года обучения это значение уменьшается до 33\%. Эти данные позволяют предположить, что процесс обучения в 6-м классе 
(с учетом коррекционных мероприятий по формированию метапредметных результатов) оказывается эффективным для формирования теоретического способа решения проблем поискового характера.

Интересно сравнить полученные нами данные с результатами исследований А.З. Зака, проведенных в 1980-х гг. Такое сравнение становится возможным, потому что в работе А.З. Зака была использована та же диагностическая методика «Перестановки», что и в нашем исследовании. По его данным (Зак, 1984), содержательную рефлексию продемонстрировали 32\% выпускников начальной школы, а способность к целостному планированию - 52\% выпускников. В контексте его исследования эти данные, полученные на небольшой выборке (160 учащихся) выпускников начальных школ, обучавшихся по стандартным учебным программам, статистически значимо уступали результатам учащихся, обучавшихся по программе РО (148 человек). К тому же в то время в российском образовании на начальную школу отводилось всего три года обучения. Т.е. эти результаты демонстрировали учащиеся, обучавшиеся всего три года по стандартным образовательным программам. Сравнение этих результатов с современными данными приведено в таблице 8.

Таблица 8

Число учащихся со сформированным третьим уровнем познавательной рефлексии и умения планировать свои учебные действия, \%

\begin{tabular}{|l|c|c|c|c|}
\hline & $\begin{array}{c}\mathbf{1 9 8 0} \\
\text { Выпускники } \\
\text { начальной } \\
\text { школы } \\
\text { (данные } \\
\text { А.З. Зака) }\end{array}$ & $\begin{array}{c}\mathbf{2 0 1 1} \\
\text { Выпускники } \\
\text { начальной } \\
\text { школы (предва- } \\
\text { рительная } \\
\text { диагностика) }\end{array}$ & $\begin{array}{c}\text { Поятиклассники } \\
\text { (первый этап } \\
\text { диагностики) }\end{array}$ & $\begin{array}{c}\text { Шестиклассники } \\
\text { (второй этап } \\
\text { диагностики) }\end{array}$ \\
\hline $\begin{array}{l}\text { Познавательная } \\
\text { рефлексия }\end{array}$ & 32 & 8.5 & 10 & 10 \\
\hline $\begin{array}{l}\text { Умение } \\
\text { планировать }\end{array}$ & 52 & 7.5 & 13 & 25 \\
\hline
\end{tabular}

Как видно из таблицы, результаты учащихся основной школы (5-е, 6-е классы) значительно ниже результатов выпускников начальной школы почти 40 лет назад. В настоящее время число школьников, способных осознать существенные отношения задачи, выделить общий способ решения, построить целостную программу практических действий, необходимых для решения задачи, уменьшилось в 2-7 раз. Этот факт ставит перед нами множество вопросов, касающихся изменений в системе начального образования в нашей стране за это время. Вероятно, он может быть связан как с изменениями в учебном содержании, так и в организации образовательного процесса. Поиск психологических факторов и механизмов, влияющих на формирование метапредметных результатов в начальной школе и на этапе перехода в основную школу, будет являться содержанием наших дальнейших исследований. 


\section{Литература}

Белова, С. Е., Дьякова, Т. Л., Елагина, С. Б., и др. (2016). Обучаем в деятельности. Пособие для учителей начальной школьь. Режим доступа: http://mosmetod.ru/metodicheskoe-prostranstvo/nachalnaya-shkola/metodicheskie-rekomendatsii/obuchaem-v-deyatelnosti-posobie-dlyauchitelej-nachalnoj-shkoly.html

Выготский, Л. С. (1996). Психология развития как феномен культуры. М.: Институт практической психологии.

Высоцкая, Е. В., Зак, А. З., Митина, О. В., Улановская, И. М., и др. (2015). Оченка метапредметных компетениий выпускников начальной школы. М.: ГБОУ ВПО «МГППУ». Режим доступа: http://www.psychlib.ru/inc/absid.php?absid=234019

Высоцкая, Е. В., Улановская, И. М., Янишевская, М. А. (2017). Образовательная среда школы и качество метапредметного результата: проблемы формирования. В кн. Личность, интеллект, метакогнищи: исследовательские подходы и образовательные практики: материалы II Международной научно-практической конферениии (с. 473-481). Калуга: КГУ им. К. Э. Циолковского.

Давыдов, В. В. (2004). Проблемы развивающего обучения. М.: Академия.

Зак, А. 3. (1984). Развитие теоретического мышления у младиих школьников. М.: Педагогика.

Зак, А. З., Сорокова, М. Г. (2017). Оценка сформированности познавательных и регулятивных метапредметных компетенций выпускников начальной школы (при решении сюжетно-логических задач). Психологическая наука и образование, 9(1), 1-14. doi:10.17759/psyedu.2017090101

Зак, А. З., Улановская, И. М. (2017). Оценка сформированности познавательных компетенций у младших подростков. В кн. Е. Ю. Гуляева (ред.), Инновационные технологии в науке и образовании: сборник статей VI международной научно-практической конференции (Т. 2, с. 201-208). Пенза: МЦНС «Наука и Просвещение».

Савинов, Е. С. (2010). Примерная основная образовательная программа образовательного учреждения. Начальная школа. М.: Просвещение.

Улановская, И. М. (2014). Компьютерный пакет методик оценки метапредметных результатов начальной школы. Психологиеская наука и образование, 6(2), 306-319.

Улановская, И. М., Обухова, О. Л., Ривина, И. В., Поливанова, Н. И. (2017). О соотношении показателей понимания текста как метапредметного результата и школьной успеваемости на этапе перехода в основную школу. В кн. Личность, интеллект, метакогниции: исследовательские подходы и образовательные практики: материаль ІІ Международной научно-практической конференции (с. 562-569). Калуга: КГУ им. К. Э. Циолковского.

Федеральный государственный образовательный стандарт начального общего образования. (2009). Режим доступа: https://kpfu.ru/docs/F2009061155/FGOS.NOO_23_10_09_Minjust_3._1_.pdf

Рубцов Виталий Владимирович - президент МГППУ, доктор психологических наук, профессор, действительный член Российской академии образования, член президиума РАО. Сфера научных интересов: детская психология, педагогическая психология, психология развивающего образования в системе Д.Б. Эльконина - В.В. Давыдова, исследование психологических закономерностей и механизмов организации совместной учебной деятельности.

Контакты: rectorat@list.ru 
Высоцкая Елена Викторовна - ведущий научный сотрудник, ФГБНУ «Психологический институт $\mathrm{PAO»,} \mathrm{кандидат} \mathrm{психологических} \mathrm{наук.}$

Сфера научных интересов: формирование научно-теоретического мышления у подростков, организация развивающего обучения естествознанию и другим школьным предметам.

Контакты: h_vysotskaya@mail.ru

Зак Анатолий Залманович - ведущий научный сотрудник, ФГБНУ «Психологический институт $\mathrm{PAO»,} \mathrm{доктор} \mathrm{психологических} \mathrm{наук,} \mathrm{профессор.}$

Сфера научных интересов: развитие мышления детей в онтогенезе, диагностика мышления дошкольников и школьников, условия формирования мышления дошкольников и школьников 1-6-х классов.

Контакты: jasmin67@mail.ru

Улановская Ирина Михайловна - ведущий научный сотрудник, ФГБНУ «Психологический институт РАО», кандидат психологических наук.

Сфера научных интересов: исследования в области психологии образования: психологические особенности построения и использования компьютерных обучающих программ; организация коллективно-распределенной учебной деятельности; подходы и методы оценки образовательной среды школы; подходы и методы диагностики метапредметных результатов начального образования.

Контакты: iulanovskaya@mail.ru

Янишевская Мария Алексеевна - ведущий научный сотрудник, ФГБНУ «Психологический институт РАО», кандидат психологических наук.

Сфера научных интересов: психологические механизмы усвоения школьных предметов; содержание обучения в образовательной системе Д.Б. Эльконина - В.В. Давыдова; формирование метапредметных компетенций средствами школьных предметов.

Контакты: y_maria@mail.ru

\title{
The Dynamics of Meta-Subject Educational Results in Primary School at the Stage of Transition to Secondary School
}

\author{
V.V. Rubtsova , E.V. Vysotskaya ${ }^{a}$, A. Z. Zak ${ }^{a}$, I.M. Ulanovskaya ${ }^{a}$, M.A. Yanishevskaya ${ }^{a}$ \\ ${ }^{a}$ Psychological Institute of the Russian Academy of Education, 9 Bld 4 Mokhovaya Str., Moscow, 125009, \\ Russian Federation
}

\begin{abstract}
The article presents the data of diagnostic research that determined the formation levels of meta-subject educational results: the development of initial forms of cognitive reflection, ways to solve search problems, the ability to plan for students in Grades 5 and 6 (the transition to secondary school). The study involved 517 students from 14 schools in Moscow and from a small town near Moscow. The meta-subject educational results were determined using the method of Replacements (authored by A. Z. Zack). The data of preliminary diagnostics obtained during the survey of more than 2000 primary school graduates in 2011 was taken as a "reference point". The dynamics of meta-subject results during training in the transitional 5th and 6th grades of secondary
\end{abstract}


school were treated. The qualitative levels of cognitive reflection (conceptual or meaningful reflection, formal reflection, no reflection), the ability to solve search problems (the solution is carried out in a general way, the solution is performed in a particular or concrete way, no method of solving search problems) and the ability to plan (entire planning, empirical planning, no planning). It is shown that the level of meta-subject results of fifth graders is quite low: meaningful reflection is noted in $7.4 \%$ of students, the ability to solve problems in a general way - in $30.5 \%$, and entire planning - in $10.2 \%$ of children. There is some positive dynamics during the training in Grade 6: conceptual reflection is demonstrated by $11.7 \%$ of sixth-graders, the ability to solve problems in a general way - by $46.1 \%$ of children, and entire, holistic planning - by $28.1 \%$. In conclusion, the comparison of obtained data with the results of the same Replacements Method (data of primary school graduates in 1980) is discussed.

Keywords: meta-subject educational results, cognitive reflection, the ability to plan, the ability to solve search problems, the stage of transition to secondary school.

\section{References}

Belova S. E., D'yakova T. L., Elagina S. B., et al. (2016). Obuchaem v deyatel'nosti. Posobie dlya uchitelei nachal'noi shkoly [Training in an activity. A primary teacher's manual]. Retrieved from http://mosmetod.ru/metodicheskoe-prostranstvo/nachalnaya-shkola/metodicheskie-rekomendatsii/obuchaem-v-deyatelnosti-posobie-dlya-uchitelej-nachalnoj-shkoly.html (in Russian)

Davydov, V. V. (2004). Problemy razvivayushchego obucheniya [Problems of developmental learning]. Moscow: Academia. (in Russian)

Federal'nyi gosudarstvennyi obrazovatel'nyi standart nachal'nogo obshchego obrazovaniya [The Federal State Educational Standard for Primary General Education]. (2009). Retrieved from https://kpfu.ru/docs/F2009061155/FGOS.NOO_23_10_09_Minjust_3._1_.pdf

Savinov, E. S. (2010). Primernaya osnovnaya obrazovatel'naya programma obrazovatel'nogo uchrezhdeniya. Nachal'naya shkola [The guidelines for a basic educational program in an educational institution. Primary school]. Moscow: Prosveshchenie. (in Russian)

Ulanovskaya, I. M. (2014). Komp'yuternyi paket metodik otsenki metapredmetnykh rezul'tatov nachal'noi shkoly [A computer based set of assessment methods for meta-subject educational outcomes in primary school]. Psikhologicheskaya Nauka i Obrazovanie, 6(2), 306-319. (in Russian)

Ulanovskaya, I. M., Obukhova, O. L., Rivina, I. V., \& Polivanova, N. I. (2017). O sootnoshenii pokazatelei ponimaniya teksta kak metapredmetnogo rezul'tata i shkol'noi uspevaemosti na etape perekhoda v osnovnuyu shkolu [On the correlation of indicators of text comprehension as a metasubject result and school performance at the stage of transition to primary school]. In Lichnost', intellekt, metakognitsii: issledovatel'skie podkhody i obrazovatel'nye praktiki: materialy II Mezhdunarodnoi nauchno-prakticheskoi konferentsii [Personality, Intelligence, Metacognition: Research Approaches and Educational Practices: Proceedings of the II International Scientific and Practical Conference] (pp. 562-569). Kaluga: KGU im. K. E. Tsiolkovskogo. (in Russian)

Vygotsky, L. S. (1996). Psikhologiya razvitiya kak fenomen kultury [Development psychology as a cultural phenomenon]. Moscow: Institut prakticheskoi psikhologii. (in Russian) 
Vysotskaya, E. V., Zak, A. Z., Mitina, O. V., Ulanovskaya, I. M., et. al. (2015). Otsenka metapredmetnykh kompetentsii vypusknikov nachal'noi shkoly [Evaluation of meta-subject competencies in elementary school graduates]. Moscow: GBOU VPO "MGPPU”. Retrieved from http://www.psychlib.ru/inc/absid.php?absid=234019 (in Russian)

Vysotskaya, E. V., Ulanovskaya, I. M., \& Yanishevskaya, M. A. (2017). Obrazovatel'naya sreda shkoly i kachestvo metapredmetnogo rezul'tata: problemy formirovaniya [The educational environment of school and the quality of meta-subject outcomes: problems of formation]. In Lichnost', intellekt, metakognitsii: issledovatel'skie podkhody i obrazovatel'nye praktiki: materialy II Mezhdunarodnoi nauchno-prakticheskoi konferentsii [Personality, Intelligence, Metacognition: Research Approaches and Educational Practices: Proceedings of the II International Scientific and Practical Conference] (pp. 473-481). Kaluga: KGU im. K. E. Tsiolkovskogo. (in Russian)

Zak, A. Z. (1984). Razvitie teoreticheskogo myshleniya u mladshikh shkol'nikov [The development of theoretical thinking in younger students]. Moscow: Pedagogika. (in Russian)

Zak, A. Z., \& Ulanovskaya, I. M. (2017). Otsenka sformirovannosti poznavatel'nykh kompetentsii u mladshikh podrostkov [The assessment of the formation of cognitive competencies in younger adolescents]. In E. Yu. Gulyaeva (Ed.), Innovatsionnye tekhnologii v nauke i obrazovanii: sbornik statei VI mezhdunarodnoi nauchno-prakticheskoi konferentsii [Innovative technologies in science and education: a collection of papers for the VI International Scientific and Practical Conference] (Vol. 2, pp. 201-208). Penza: MTsNS "Nauka i Prosveshchenie". (in Russian)

Zak, A. Z., \& Sorokova, M. G. (2017). Otsenka sformirovannosti poznavatel'nykh i regulyativnykh metapredmetnykh kompetentsii vypusknikov nachal'noi shkoly (pri reshenii syuzhetno-logicheskikh zadach) [Assessing the levels of cognitive and regulatory meta-subject competences in primary school graduates]. Psikhologicheskaya Nauka i Obrazovanie, 9(1), 1-14. doi:10.17759/psyedu.2017090101 (in Russian)

Vitaliy V. Rubtsov - D.Sc., professor of Psychology, a Full Member of the Russian Academy of education (RAE), a Member of the Presidium of RAE.

Research area: child psychology, educational psychology, the content of education in the Elkonin-Davydov educational system, the research of psychological laws and mechanisms of organizing joint educational activities.

E-mail: rectorat@list.ru

Elena V. Visotskaya - leading research fellow, FGBNU "Psychological Institute of Russian Academy of Education", Ph.D.

Research area: development of theoretical thinking in teenagers, the content of education in the Elkonin-Davydov educational system, the developing content in natural science education.

E-mail: h_vysotskaya@mail.ru

Anatoliy Z. Zak - leading research fellow, FGBNU "Psychological Institute of Russian Academy of Education", D.Sc., professor.

Research area: mechanisms of thinking development in ontogenesis, assessment of thinking abilities in preschoolers and schoolchildren. 
E-mail: jasmin67@mail.ru

Irina M. Ulanovskaya - leading research fellow, FGBNU "Psychological Institute of Russian Academy of Education", Ph.D.

Research area: characteristics of school educational environment, the content and organization of joint learning activities in the Elkonin-Davydov educational system, assessment of meta-subject educational results.

E-mail: iulanovskaya@mail.ru

Maria A. Yanishevskaya - leading research fellow, FGBNU "Psychological Institute of Russian Academy of Education", Ph.D.

Research area: psychological mechanisms of mastering school subjects; the content of education in the Elkonin-Davydov educational system; development of meta-subject competencies by means of school subjects.

E-mail: y_maria@mail.ru 